\title{
The Role of PKC $\delta$ and PKC $\epsilon$ in the Neonatal Rat Colon in Response to Hypoxia Challenge
}

\author{
MELISSA CONTE, BRIAN SOPER, QING CHANG, AND BARRY TEPPERMAN \\ Department of Physiology and Pharmacology, Faculty of Medicine and Dentistry, The University of \\ Western Ontario, London, Ontario, Canada N6A 5C1
}

\begin{abstract}
Previous studies have determined that, in response to bacterial endotoxin, the colonic mucosa of the 10-d-old neonatal rat was more susceptible to injury than was the colon of the 25-d-old mature animal. Furthermore, it is known that certain isoforms of protein kinase $\mathrm{C}(\mathrm{PKC})$, specifically $\mathrm{PKC} \delta$ and $\mathrm{PKC} \epsilon$, mediate intestinal inflammatory responses to specific challenges. Therefore, in the present study, we have examined the association between the activation of these PKC isoforms and the enhanced susceptibility to hypoxia-induced challenge. In response to exposure to a hypoxic environment $\left(14 \% \mathrm{O}_{2} / 86 \% \mathrm{~N}_{2}, 30 \mathrm{~min}\right)$, the degree of inflammation and tissue damage was significantly greater in 10- than in 25-d-old rats. The injury in 10-d-old rats was associated with activation of PKC $\delta$ and PKC $\epsilon$ as estimated by translocation of the isoform from cytosolic to membrane fraction of the tissue lysate. There was no activation of either isoform in colons from 25-d-old rats after hypoxia. Pretreatment of 10-d-old rats with epidermal growth factor (EGF) $(10 \mu \mathrm{g} / \mathrm{kg})$ but not 16,16 dimethyl prostaglandin $\mathrm{E}_{2}(2 \mu \mathrm{g} / \mathrm{kg})$ significantly reduced the extent of colonic injury, whereas neither agent was able to exert significant protection of the colonic mucosa of
\end{abstract}

\section{ABSTRACT}

25-d-old rats. PKC activation associated with hypoxia was not evident after EGF treatment in 10-d-old rats. In 25-d-old rats, prostaglandin $\mathrm{E}_{2}$ treatment was linked with an activation of PKC $\epsilon$ only. In conclusion, these data suggest that activation of $\mathrm{PKC} \delta$ and $\mathrm{PKC} \epsilon$ is associated with the enhanced susceptibility to injury evident in suckling neonatal rat colon. EGF-mediated protection of the colon in these animals results in a removal of this PKC activation. (Pediatr Res 55: 27-33, 2004)
dmPGE dimethyl prostaglandiation
EGF, epidermal growth factor
MDA, malondialdehyde
MPO, myeloperoxidase
NOS, nitric oxide synthase
PAF, platelet activating factor
PKC, protein kinase C
TNBS, trinitrobenzensulfonic acid
TNF, tumor necrosis factor

It has been shown previously that the gastrointestinal mucosa of preweaned rat appears to have a differential susceptibility to damage, with the lower bowel of the neonata being more sensitive to a challenge when compared with postweaned, mature animals (1). When treated with bacterial endotoxin, the neonatal colonic mucosa of suckling 10-d-old rats was found to be more severely damaged than was the colon of mature 25-d-old animals.

In addition to endotoxin treatment, the intestinal mucosa of neonatal rats appears to be highly sensitive to other challenges, including intestinal ischemia reperfusion (2). In these studies, subclinical ischemia-reperfusion or hypoxia-mediated injury resulted in an enhanced degree of ileal mucosal permeability in

Received March 19, 2003; accepted July 28, 2003.

Correspondence: Barry L. Tepperman, Department of Physiology and Pharmacology, The University of Western Ontario, Medical Science Bldg., Room M226, London, Ontario, Canada N6A 5C1; e-mail: btepperm@med.uwo.ca

Supported by a grant from the Canadian Institutes for Health Research, Ottawa, Ontario, Canada.

DOI: 10.1203/01.PDR.0000099749.83960.CF 10-d-old rats. We have also demonstrated that hypoxia challenge in suckling rats resulted in an increase in neutrophil infiltration (3)

The reasons for this difference in susceptibility to injury in the neonatal rat are uncertain. However, there are a number of factors that may contribute to this phenomenon, including higher levels of some proinflammatory enzymes such as xanthine oxidase (4), inducible NOS (1), and enhanced production and expression of IL-4 and IL-6 (5) in neonatal animals.

$\mathrm{PKC}$ is a family of serine-threonine proteases that have been implicated in many cellular signaling pathways (6). In addition to its signal transduction role, PKC has also been associated with inflammation in a number of tissues, including the ileal and colonic mucosa (7-9). Specifically, it has been demonstrated that $\mathrm{PKC} \delta$ and $\mathrm{PKC} \epsilon$ become elevated in colonic mucosa in response to endotoxin or TNBS challenge, whereas these same isoforms are selectively activated in intestinal epithelial cells in response to TNF- $\alpha$ treatment. It has also been demonstrated that activation of $\mathrm{PKC} \delta$ is required for oxidant- 
induced disruption of the cytoskeletal structure and permeability barrier characteristics of the colonic epithelial barrier in vitro (10)

Evidence also suggests that there is an age-dependent modulation of PKC isoforms in a number of tissues, including heart, kidney, and brain (11-13). However, it is not known whether PKC undergoes similar ontogenic changes in rodent colonic mucosa. Therefore, in the present study, we have investigated changes in $\mathrm{PKC} \delta$ and $\mathrm{PKC} \epsilon$ in the colonic mucosa of 10- and 25-d-old rats and determined whether the activation of these isoforms is associated with the changes observed in susceptibility to hypoxia-induced tissue inflammation and injury.

\section{MATERIALS AND METHODS}

Animals. Male and female Sprague-Dawley rat pups, aged 8 and $23 \mathrm{~d}$ postpartum, were purchased from Canada Breeding Labs (Quebec, Canada) for all experiments. Animals were maintained in a temperature-controlled environment $\left(22^{\circ} \mathrm{C}\right)$ with a 12-h light-dark cycle, and used $2 \mathrm{~d}$ after arrival. All pups were maintained with their natural mother, with chow and water available ad libitum. All studies were approved by the University of Western Ontario Animal Care Committee (protocol 2001-251-12) and all animals were treated according to the guidelines set out by the Canadian Council on Animal Care.

Treatments. At 10 and 25 d postpartum, rats of either sex were randomized into control and hypoxia groups. All rats were removed from their mothers. The group receiving hypoxia was placed in an airtight container filled with $14 \% \mathrm{O}_{2} /$ $86 \% \mathrm{~N}_{2}$ for $30 \mathrm{~min}$. Exposure to this reduced oxygen atmosphere for $30 \mathrm{~min}$ has previously been shown to cause intestinal epithelial dysfunction (3). Control animals were treated identically except under normoxic conditions. Some groups of animals were treated before hypoxia with either EGF $(10 \mu \mathrm{g} / \mathrm{kg}$ i.p.; ICN Biomedicals, Cleveland, OH, U.S.A.) or $16,16 \mathrm{dmPGE}_{2}(2 \mu \mathrm{g} / \mathrm{kg}$ i.p.; Cayman Chemical, Ann Arbor, MI, U.S.A.) $15 \mathrm{~min}$ before placement in the hypoxic chamber. These doses were based on previous studies in which these agents provided protection in the stomachs of neonatal rats (14, 15). The experiment then proceeded as described above. After insult, animals were killed by cervical dislocation and the colons were excised and maintained on ice.

Measurement of MPO activity. MPO is an enzyme located in the granules of neutrophils and, as such, is an index of an inflammatory response. Mucosal MPO levels were measured in samples of whole colon taken from hypoxia and control groups of 10- and 25-d-old rats. Tissues were weighed and suspended in $50 \mathrm{mM}$ PBS containing $0.5 \%$ hexadecyltrimethylammonium bromide (pH 6.0; Sigma Chemical, St. Louis, MO, U.S.A.) at a tissue concentration of $50 \mathrm{mg} / \mathrm{mL}$ of buffer. Each sample was homogenized on ice for $10 \mathrm{~s}$ using a Polytron homogenizer and then centrifuged for $2 \mathrm{~min}$ at $4^{\circ} \mathrm{C}$. MPO activity of the supernatant was determined by adding $100 \mu \mathrm{L}$ of the supernatant to $2.9 \mathrm{~mL}$ of $50 \mathrm{mM}$ phosphate buffer containing $0.167 \mathrm{mg} / \mathrm{mL}$ $o$-dianisidine hydrochloride (Sigma Chemical) and $50 \mu \mathrm{L}$ of $1 \%$ hydrogen peroxide. The change in absorbance at $460 \mathrm{~nm}$ over a 3-min period was measured spectrophotometrically. One unit of MPO activity was defined as that which would convert $1 \mathrm{~mol}$ of hydrogen peroxide to water in $1 \mathrm{~min}$ at $22^{\circ} \mathrm{C}$. Samples were initially normalized per milligram tissue weight.

Determination of lipid peroxidation. The tissue concentration of MDA was measured to provide an index of lipid peroxidation according to a method previously described by Yagi (16). Briefly, whole-thickness samples of colon were homogenized on ice in Earle's balanced salt solution for $15 \mathrm{~s}$, producing a tissue concentration of $100 \mathrm{mg} / \mathrm{mL}$. The homogenate was then sonicated for $5 \mathrm{~s}$, and $10 \mu \mathrm{L}$ were removed for spectrophotometric determination of protein content using the Bio-Rad protein assay (Bio-Rad, Hercules, CA, U.S.A.). Trichloroacetic acid $(5 \%, 1.8 \mathrm{~mL})$ was added to $200 \mu \mathrm{L}$ of homogenate before centrifugation at $3000 \times g$ at $4^{\circ} \mathrm{C}$ for 20 $\min$. A $1.5-\mathrm{mL}$ aliquot of the supernatant was added to $1.5 \mathrm{~mL}$ of freshly prepared thiobarbituric acid $(0.6 \%)$, and the mixture was vortexed for $5 \mathrm{~s}$ and boiled for $10 \mathrm{~min}$. The colored product was extracted by addition of $2 \mathrm{~mL}$ of $n$-butanol before centrifugation at $3000 \times g$ for $15 \mathrm{~min}$ at ambient temperature. The fluorescence of the upper $n$-butanol layer was measured at an excitation wavelength of $515 \mathrm{~nm}$ and emission wavelength of $553 \mathrm{~nm}$ using tetramethoxypropane (Sigma Chemical) as the standard.

Histologic assessment of mucosal damage. Mucosal injury was determined histologically. Whole-thickness sections of distal colon were fixed in neutral-buffered formalin $(10 \%$ in PBS, $\mathrm{pH}$ 7.4), processed routinely, cut longitudinally (4 $\mu \mathrm{m}$ thickness), and stained with hematoxylin and eosin. Sections were examined by light microscopy by a naïve observer in a randomized manner, and a scoring system was used where $0=$ normal appearance; 1 = vasocongestion; 2 = submucosal edema with erythrocyte extravasation; and 3 = submucosal edema and epithelial disruption. Each section was evaluated by a naïve observer and scored on a cumulative basis to give the histologic damage score, the maximum score thus being 10.

Mucosal PKC activation. PKC protein levels in the cytosolic and membrane fraction of colonic tissue were determined to estimate the isoform's activation. Translocation of PKC from cytosol to membrane has been commonly accepted as an index of PKC activation. Translocation was defined as a decrease in PKC protein level in the cytosol and a corresponding increase in the membrane fraction of the tissue lysate. Samples of 200 $\mathrm{mg}$ of colonic tissue were suspended in $1 \mathrm{~mL}$ of a homogenization buffer consisting of $0.1 \%$ Triton X-100; $50 \mathrm{mM}$ Tris$\mathrm{HCl} ; 5 \mathrm{mM}$ EDTA; $25 \mathrm{mM}$ EGTA; $50 \mu \mathrm{g} / \mathrm{mL}$ phenylmethylsulfonyl fluoride; $25 \mu \mathrm{g} / \mathrm{mL}$ each of soybean trypsin inhibitor, leupeptin, and aprotonin; and 5\% mercaptoethanol. The samples were homogenized for $10 \mathrm{~s}$ and then centrifuged at $100,000 \times g$ for $60 \mathrm{~min}$ at $4^{\circ} \mathrm{C}$. The supernatant was collected as the cytosolic fraction. The resulting pellet was resuspended in the homogenization buffer containing $0.1 \%$ Triton X-100, mixed for $60 \mathrm{~min}$, and centrifuged again at $100,000 \times g$ at $4^{\circ} \mathrm{C}$ to remove insoluble membrane components. The resultant supernatant was kept as the particulate or membrane fraction. The protein content of each fraction was determined by the Bio-Rad assay. The particulate and cytosolic fraction extracts were prepared for electrophoresis by boiling for $5 \mathrm{~min}$ in an 
equal volume of buffer containing $125 \mathrm{mM}$ Tris $\mathrm{pH} 6.8,20 \%$ glycerol, and $10 \%$ mercaptoethanol. Each fraction was subjected to $10 \%$ SDS-PAGE and transferred to nitrocellulose membranes at $100 \mathrm{~V}$ for $75 \mathrm{~min}$. After blocking nonspecific binding sites with $10 \%$ nonfat milk in PBS-Tween buffer ( 80 $\mathrm{mM} \mathrm{Na} \mathrm{HPO}_{4}, 10 \mathrm{mM} \mathrm{NaCl}, 20 \mathrm{mM} \mathrm{NaH} \mathrm{PO}_{4}$, and $0.05 \%$ Tween-20), the membranes were incubated for $3 \mathrm{~h}$ with specific PKC PKC $\epsilon$ and $\delta$ antibodies (1:1000) (Santa Cruz Biotechnology, Santa Cruz, CA, U.S.A.) at room temperature followed by incubation with 1:6000 dilution of horseradish peroxidase-conjugated anti-rabbit IgG (Jackson ImmunoResearch Laboratories, West Grove, PA, U.S.A.) for $1 \mathrm{~h}$ at room temperature and then detected with ECL reagents according to the manufacturer's instructions (Amersham Pharmacia Biotech, Inc., Piscataway, NJ, U.S.A.). The peptide used to raise the antibody was used in competition studies to demonstrate specificity of the polyclonal antibody. Equal loading of proteins of the gel was verified by $10 \%$ SDS-PAGE stained with Coomassie Blue (R250). The results were determined by densitometric analysis of blots using the imageMaster DTS software (Amersham Pharmacia Biotech).

PKC mRNA determination. The total RNA was isolated from rat colonic mucosa by Trizol reagent following the manufacturer's procedure. The integrity of RNA extracts was assessed on a $1.5 \%$ agarose gel and RNA was visualized by ethidium bromide staining. The amount of total RNA was determined spectrophotometrically.

First-strand cDNA was synthesized using transcript reverse transcriptase, oligo (DT) primers (Invitrogen, Carlsbad, CA, U.S.A.) at $37^{\circ} \mathrm{C}$ for $60 \mathrm{~min}$ in a final volume of $20 \mu \mathrm{L}$. Total RNA of $1 \mu \mathrm{g}$ was adjusted to remain well within the exponential amplification range. Reactions containing no reverse transcriptase were performed as a negative control. PKC $\delta$ (5'CACCATCTTCCAGAAGAACG, 3'GTTGTTGCCCTGGATACCGTTC) and PKC $\epsilon$ (5'CGAGGACGACTTGTTGAATTC, 3'CTGGACTACGGGACTCTTTGAC) isoformspecific primers, based on reported sequences from GenBank were designed. Glyceraldehyde phosphate dehydrogenase (GAPDH) was used as an internal standard. A volume of $1 \mu \mathrm{L}$ of the reverse transcriptase cDNA sample was used to perform the PCR reaction in a $50 \mu \mathrm{L}$ volume with 1.25 units Tag DNA polymerase for 30 cycles with an amplification program of denaturation $\left(95^{\circ} \mathrm{C}, 45 \mathrm{~s}\right)$, primer annealing $\left(59^{\circ} \mathrm{C}, 45 \mathrm{~s}\right)$, and primer extension $\left(74^{\circ} \mathrm{C}, 1 \mathrm{~min}\right)$. In each case, it was determined that the amplification occurred with similar efficiencies and that the products were well within the linear range of curves with standard amounts of tissue RNA.

The PCR-amplified products were electrophoresed on a $1.5 \%$ agarose gel and visualized with ethidium bromide staining. The band intensity was measured in the same way as described above. The ratio of mRNA or each isoform to that of GAPDH was determined in the colonic tissue of each rat.

Statistical analysis. Results are presented as means \pm SE for $n$ animals. Data were analyzed by ANOVA using the Dunnett test for multiple comparisons and Student-Newman-Keuls test for paired analysis. A $p$ value $<0.05$ was the minimum accepted level of significance for all groups.

\section{RESULTS}

Exposure of 10- and 25-d-old rats to a hypoxic environment for $30 \mathrm{~min}$ resulted in a significant increase in MPO activity in the colonic tissue (Fig. 1A). The extent of MPO increase in 10-d-old rats was significantly greater in the older group of animals. Similarly, hypoxia resulted in a significant increase in tissue lipid peroxidation as assessed by MDA levels (Fig. 1B). The extent of the increase in MDA was once again greater in the 10-d-old rats compared with the 25-d-old animals.
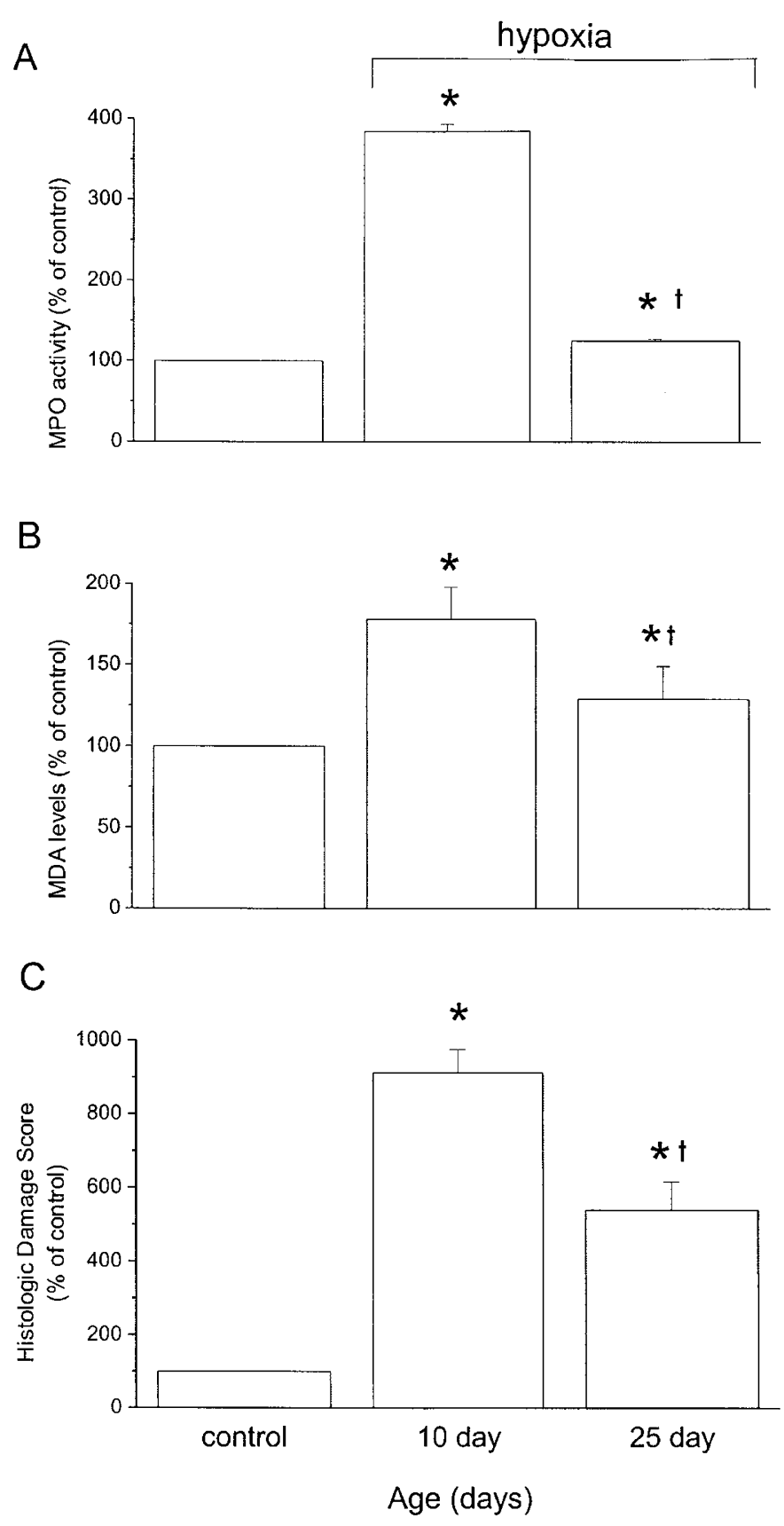

Figure 1. The effect of hypoxia on 10- and 25-d-old rats on colonic tissue inflammation as assessed by $(A)$ MPO activity, $(B)$ lipid peroxidation as assessed by the MDA assay, and $(C)$ histologic damage score. Data are expressed as the percentage of control levels and are the means ( \pm SE) of results from seven to nine rats per group. Asterisks indicate significant differences from respective control and crosses indicate significant differences between 10- and 25-d-old rats. 
Whole-thickness sections of distal colon were examined for evidence of histologic abnormalities. The appearance of the serosa, muscularis, and mucosa of 10- and 25-d-old rats was unremarkable. However, in response to hypoxia challenge, the colons from 10-d-old rats presented with gross evidence of inflammation including vasocongestion, submucosal edema, and epithelial disruption (Fig. 1C). Whereas the 25-d-old rats also demonstrated a significant increase in the extent of histologic injury in response to hypoxia, this injury was significantly less than was observed in 10-d-old rats (Fig. 1C).

PKC $\epsilon$ and $\delta$ protein was also evident in the tissue excised from 10- and 25-d-old rats. Furthermore, hypoxia resulted in a decrease in the amount of PKC $\delta$ and PKC $\epsilon$ protein in the cytosolic fraction and a significant increase in the membrane fraction of the tissue lysate of 10-d-old rats (Fig. 2, $A$ and $B$ ). In contrast, in 25-d-old rats, there was a significant increase in the protein of both PKC isoforms in the cytosolic fraction (Fig. $3, A$ and $B$ ). There was a significant increase in the protein for $\mathrm{PKC} \delta$ but not PKC $\epsilon$ in the membrane fraction in response to hypoxia.
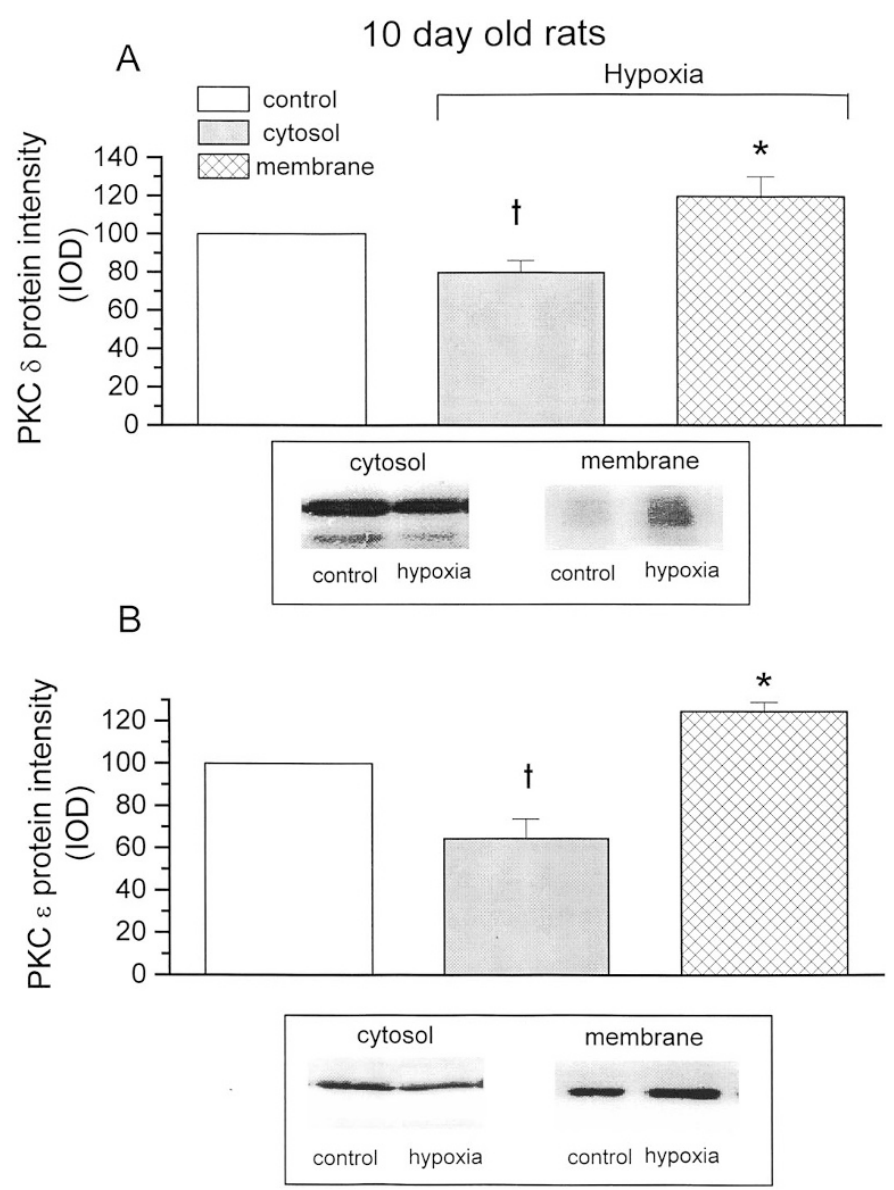

Figure 2. The effect of hypoxia on $\operatorname{PKC} \delta(A)$ and PKCPKC $\epsilon(B)$ protein levels in 10-d-old rats. PKC protein levels were determined in the cytosolic and membrane fractions of the tissue homogenate. Data are expressed relative to respective control levels and are the means $( \pm \mathrm{SE})$ of Western blots from five to six rats per group. Crosses indicate significant decreases from respective control and asterisks indicate significant increases from respective controls. Representative Western blots of each PKC isoform determined in membrane and cytosolic tissue fraction in untreated control and hypoxia-challenged animals are displayed beneath each histogram.
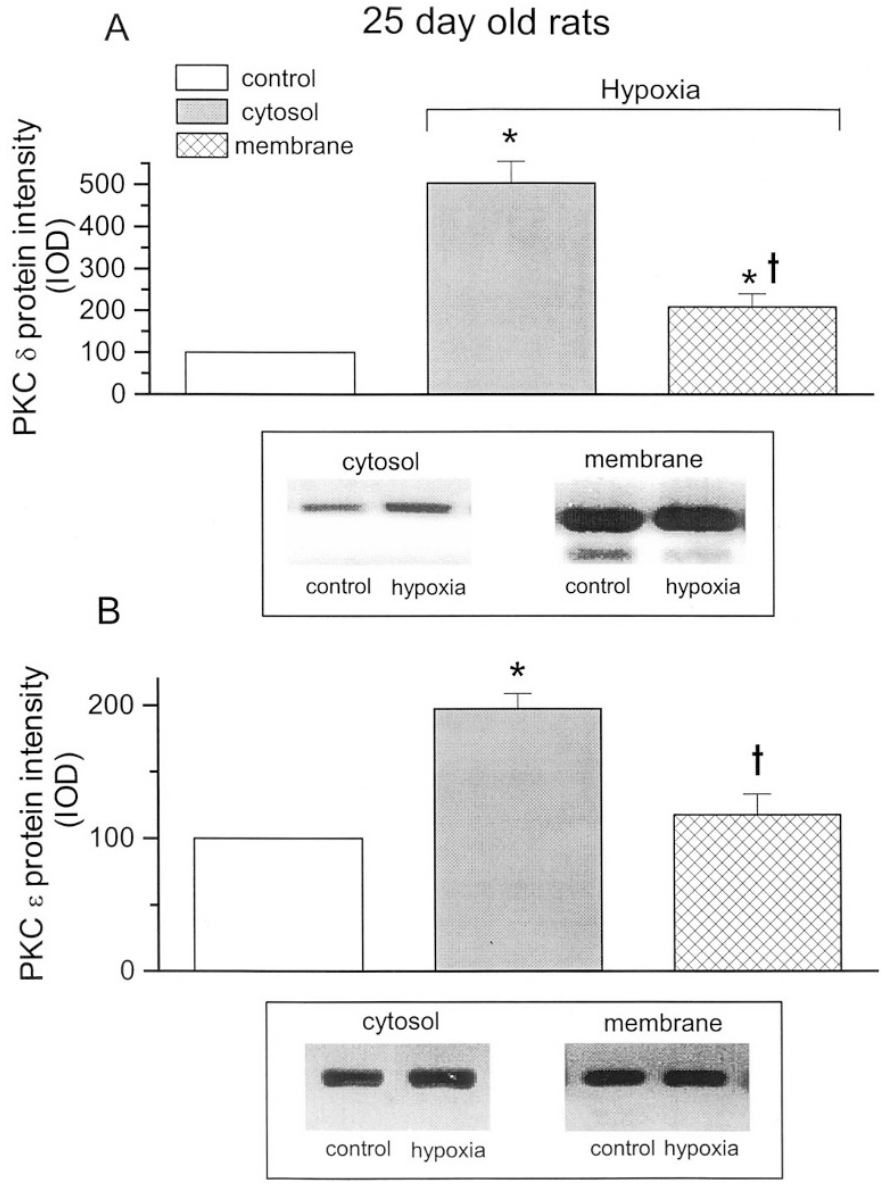

Figure 3. The effect of hypoxia on $\operatorname{PKC} \delta(A)$ and $\operatorname{PKC} \epsilon(B)$ protein levels in 25 -d-old rats. PKC protein levels were determined in the cytosolic and membrane fractions of the tissue homogenate. Data are expressed relative to respective control levels and are the means $( \pm \mathrm{SE})$ of six to eight rats per group. Asterisks indicate significant increases from respective control and crosses indicate significant differences from values obtained in the cytosolic fraction. Representative Western blots of each PKC isoform determined in membrane and cytosolic tissue fraction in control and hypoxia-challenged animals are displayed below each histogram.

The mRNA levels for PKC $\delta$ and PKC $\epsilon$ are shown in Figure $4 A$ and $B$. mRNA of PKC $\delta$ was clearly increased in response to hypoxia challenge in both 10 - and 25 -d-old rats (Fig. $4 A$ ) whereas the ratio of mRNA to GAPDH for PKC $\epsilon$, although increased, did not achieve statistical significance (Fig. $4 B$ ).

Treatment of 10-d-old animals with EGF resulted in a reduction in the extent of tissue inflammation and injury as assessed by MPO activity. However, administration of $\mathrm{dmPGE}_{2}$ to 10 -d-old rats did not produce any significant protective effects (Fig. 5A). EGF treatment significantly reduced the extent of MPO activity in 25-d-old rats after hypoxia (Fig. 5B). Prostaglandin administration appeared to produce only a small decrease in hypoxia-mediated inflammation (Fig. $5 B)$.

In response to EGF treatment in 10-d-old rats, the was no apparent translocation of either PKC isoform from cytosol to membrane (Fig. $6 A$ and $B$ ). PKC $\delta$ and PKC $\epsilon$ proteins increase slightly in the cytosol after hypoxia and EGF treatment and either decreased or remained unchanged in membrane. Prosta- 
A

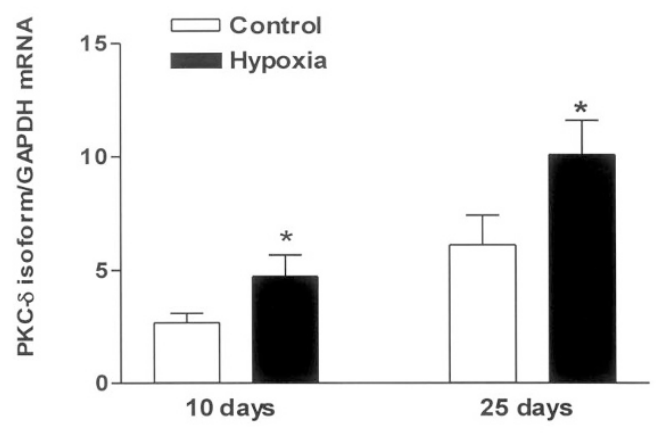

Control Hypoxia

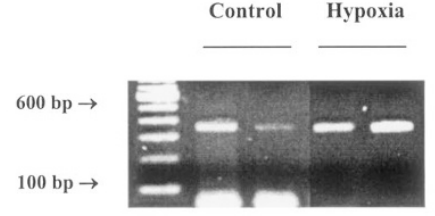

B
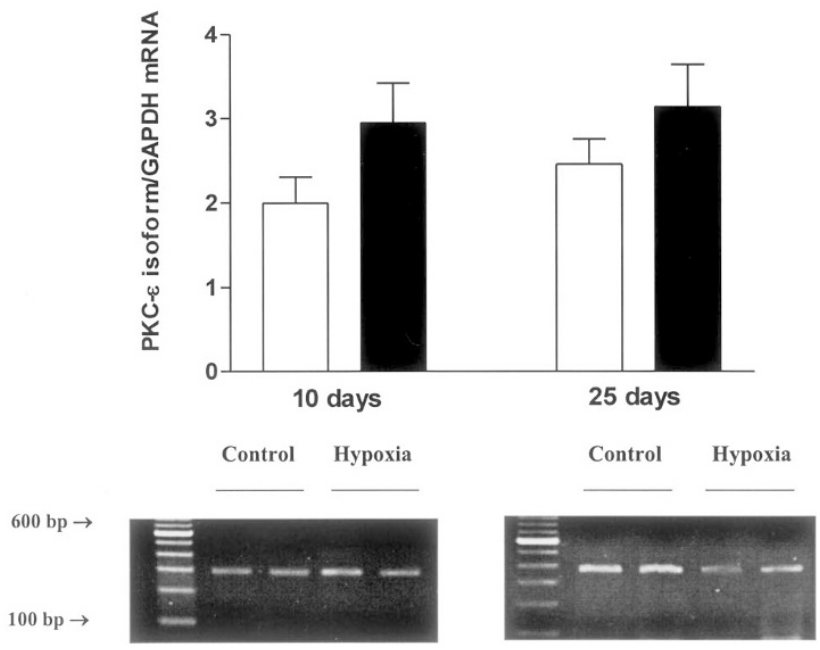

Figure 4. Gene expression of $\mathrm{PKC} \delta$ and $\mathrm{PKC} \epsilon$ in 10 - and 25 -d-old rat colonic tissue in untreated controls and hypoxia-challenged rats. mRNA levels for each PKC isoform examined were determined by quantitative PKC with GAPDH as internal control as described in "Materials and Methods." Data are the means ( $\pm \mathrm{SE}$ ) from six to eight rats per group. Asterisks indicate significant differences from respective controls.

glandin $\mathrm{E}_{2}$ treatment resulted in reduced PKC levels in both cytosol and membrane in 10-d-old rats (Fig. $6 A$ and $B$ ).

In 25-d-old animals, PKC $\delta$ did not appear to be affected by EGF treatment (Fig. $7 A$ ) as evidenced by reduced levels in both cytosol and membrane. Furthermore, EGF resulted in an increase in PKC $\epsilon$ in the cytosol fraction and no change in membrane levels. In contrast, $\mathrm{dmPGE}_{2}$ did not reduce $\mathrm{PKC} \delta$ levels in the cytosol although membrane levels were significantly increased. However, PKC $\epsilon$ was activated to a significant degree by dmPGE2 as evidenced by a decrease in cytosol and an increase in the levels in the membrane fraction (Fig. $7 B$ ).

\section{DISCUSSION}

In the present study, we have observed that exposure of 10-d-old suckling, preweaned rats to a hypoxic environment would result in a significant increase in colonic inflammation and injury. This confirms previous findings from this and other

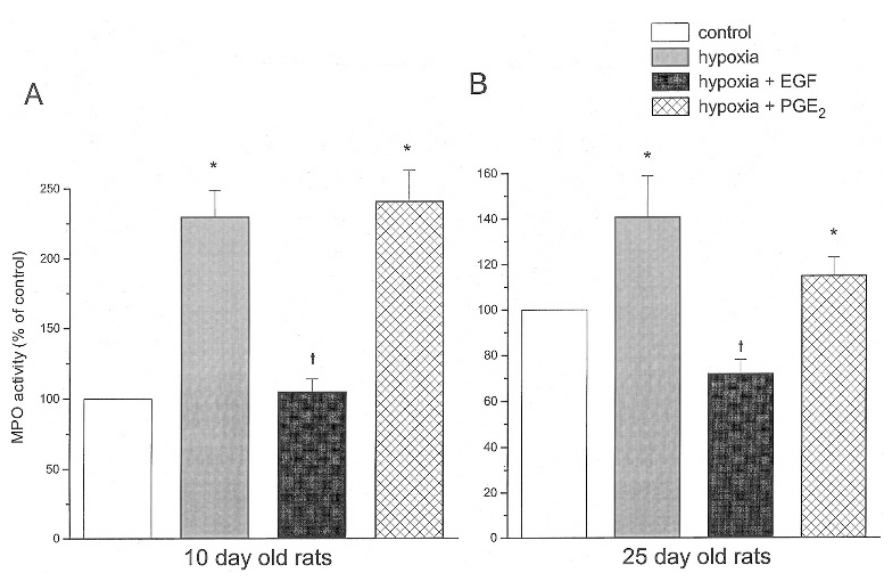

Figure 5. The effect of EGF and 16,16 $\mathrm{dmPGE}_{2}$ on MPO levels in colonic tissue from 10- $(A)$ and 25- $(B)$ d-old rats exposed to hypoxia. Data are expressed as percentage changes from respective controls and are the means $( \pm \mathrm{SE})$ from five to eight rats per group. Asterisks indicate significant increases from respective controls and crosses indicate significant differences from the MPO responses to hypoxia alone.

laboratories $(1,17,18)$. Furthermore, these data also demonstrated that this degree of injury and inflammation was greater in the preweaned rat than in postweaned 25 -d-old rats. This finding also extends our previous findings that the degree of injury in response to lipopolysaccharide treatment was greater in neonatal than in mature rats to include hypoxia-mediated tissue inflammation and lipid peroxidation (1).

The reasons for this ontogenic difference in susceptibility to injury and inflammation are unknown. However, a number of contributing factors have been suggested, including xanthine oxidase activity (4), NOS activity $(1,19)$, PAF levels (17), and cytokines such as TNF, IL-4, and IL-6 $(5,17)$. In each of the cases cited above, the potential inflammatory influence was found to be greater in the neonate than in the adult animal. In the present study, we have investigated the association between colonic levels of the PKC $\epsilon$ and $\delta$ isoforms of PKC and enhanced susceptibility to injury in the colon of the suckling neonatal animal.

In the present study, PKC levels were investigated in the colonic tissue of 10- and 25-d-old rats. Previous studies have also demonstrated PKC in neonatal tissues and have also demonstrated that there was a developmental change in PKC levels in brain, heart, and kidney, with higher levels being observed in neonatal rats $(11,12,20)$. Furthermore, our data also demonstrated that there is an activation of PKC $\epsilon$ and $\delta$ in the neonatal colon in response to hypoxia, whereas activation was not apparent in the mature animals. Activation of PKC was estimated by translocation of the isoform from cytosol to membrane fraction of the tissue lysate (a decrease in cytosolic levels of the protein and a corresponding increase in membrane levels). Previous reports have determined that this translocation phenomenon is a reliable estimation of isoform activation $(21,22)$.

The activation of these PKC proteins in neonatal animals suggests that there might be some link to the enhanced degree of susceptibility to injury and inflammation evident in these rats. Bandla and colleagues (23) have similarly hypothesized 

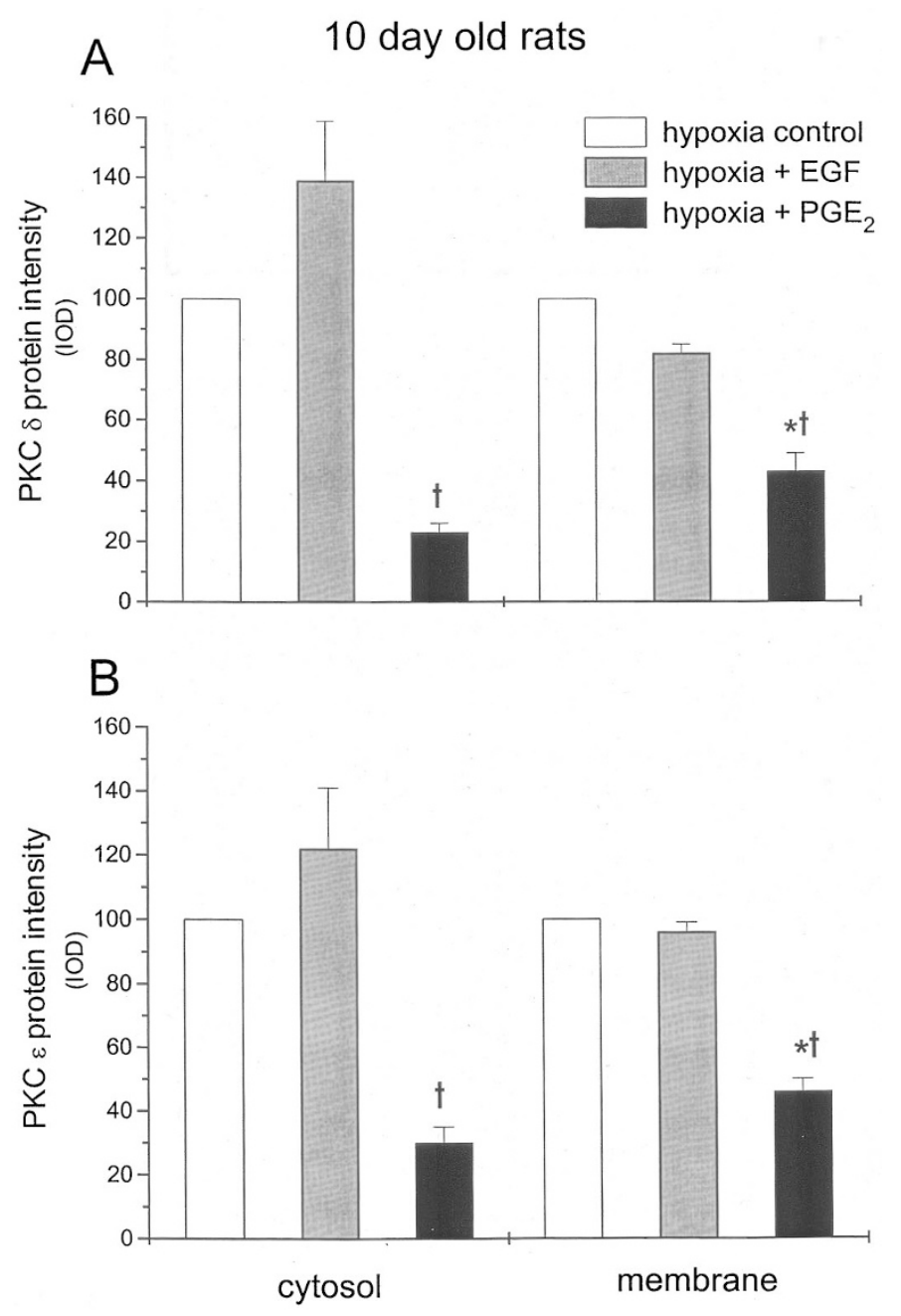

Figure 6. The effect of EGF and $16,16 \mathrm{dmPGE}_{2}$ treatment on $\mathrm{PKC} \delta(A)$ and $\mathrm{PKC} \epsilon(B)$ protein intensity in 10-d-old rats exposed to hypoxia. Data are expressed as percentage change from respective controls and are the means $( \pm$ $\mathrm{SE}$ ) of Western blots obtained from five to six rats per group. Crosses indicate significant reductions from respective controls and asterisks indicate significant differences in data between membrane and cytosolic fractions.

that the changes in ventilatory pattern in rodents are also linked to ontogenic changes in PKC activity, with the most critical dependency being evident in the immature animal. Similarly, PKC activation has been shown to be most critical in the mediation of neural damage in the neonatal brain (24). Therefore, it is possible that the activation of PKC in 10-d-old rats is causally associated with the enhanced susceptibility to damage in the colon.

In some cases, we observed that the PKC protein levels increased in the cytosolic fraction in response to hypoxia. We also observed that PKC levels in the membrane fraction could be reduced by treatment. This phenomenon is difficult to explain, although it may be speculated that such a response may be related to an accumulation of PKC from cytosolic sources or an increase in PKC metabolism at the membrane level. Such results may also reflect the fact that experiments were done using whole-thickness mucosa. Thus, this change may not be due exclusively to changes in PKC within the colonic mucosa.
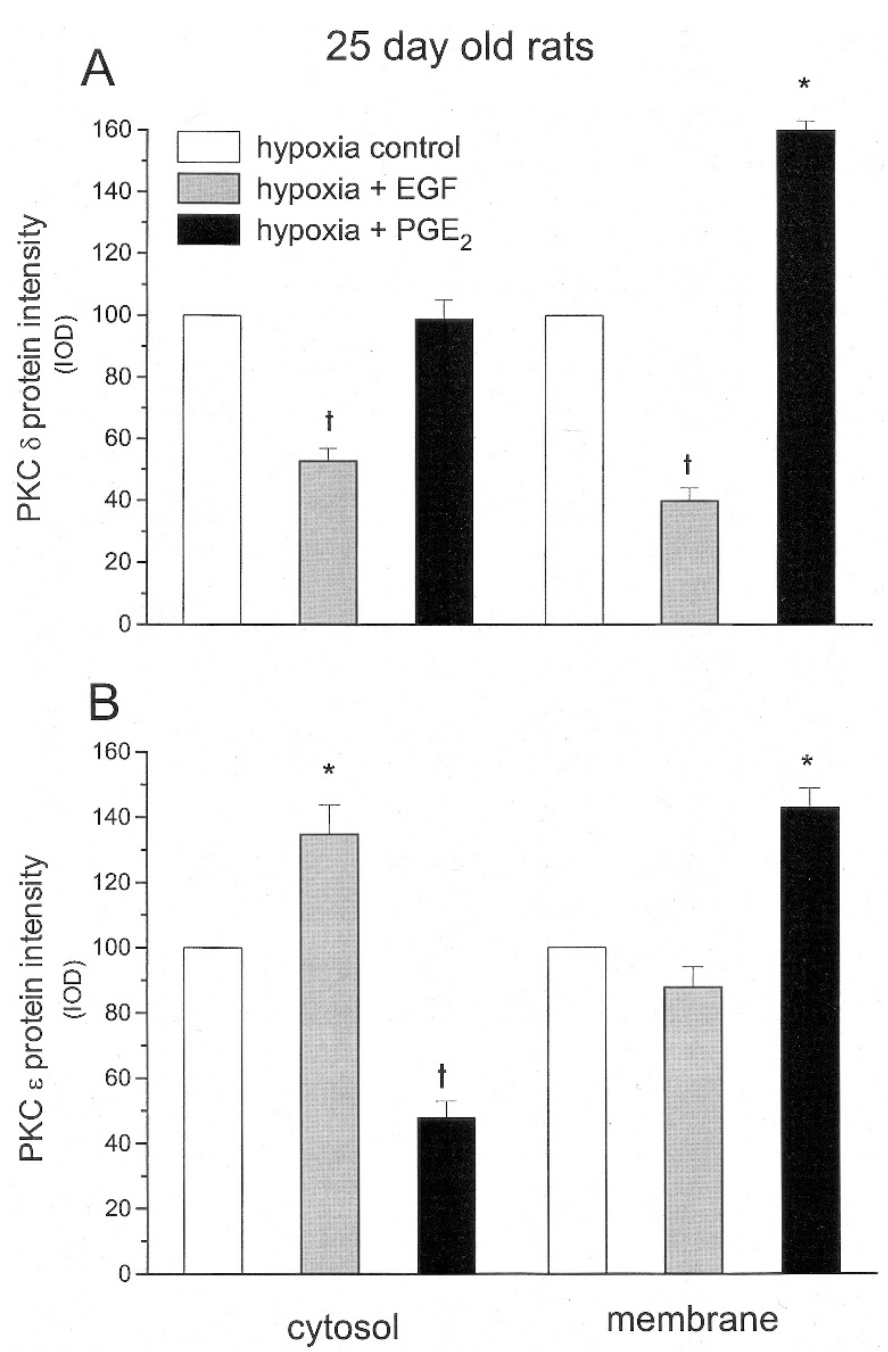

Figure 7. The effect of EGF and $16,16 \mathrm{dmPGE}_{2}$ treatment on $\mathrm{PKC} \delta(A)$ and $\mathrm{PKC} \epsilon(B)$ protein intensity in 25 -d-old rats exposed to hypoxia. Data are expressed as percentage change from respective controls and are the means $( \pm$ $\mathrm{SE}$ ) of Western blots obtained from five to seven rats per group. Crosses indicate significant reductions from respective controls and asterisks indicate significant differences in data between membrane and cytosolic fractions.

We have demonstrated that administration of EGF but not $16,16 \mathrm{dmPGE}_{2}$ to the neonatal rat would reduce the degree of hypoxia-induced colonic inflammation, whereas the same doses of both of these agents produced some degree of protection in the 25-d-old rat. This is consistent with previous literature in which EGF appears to play a significant protective role, especially in the neonatal rat model of necrotizing enterocolitis (25). Prostaglandin, however, does not appear to play a significant role in development of the neonatal intestine, although there are a number of reports indicating that exogenous prostaglandin administration can protect the adult intestine from an injurious challenge $(26,27)$. Furthermore, our data indicate that the protective effects of EGF on the 10-d-old rat colon are associated with changes in the activation status of the PKC isoforms studied here. The translocation of PKC $\delta$ and PKC $\epsilon$ in response to hypoxia were inhibited by EGF treatment in the suckling rat. PKC has been shown to mediate the protective effects of EGF on colonic monolayers in vitro (28, 29). However, these studies have focused on $\mathrm{PKC} \beta 1$ rather 
than $\mathrm{PKC} \delta$ and $\mathrm{PKC} \epsilon$. It is not known whether the differences in dependency on the different PKC isoforms reflect variances in cell model and/or injurious challenge used in these experiments. Similarly, the protective effects of $\mathrm{PGE}_{2}$ on intestinal epithelial cells have also been shown to be mediated by $\mathrm{PKC}$, although the precise PKC isoform has not been previously determined in that study (30). However, it has been demonstrated that PKC $\epsilon$ may mediate the protective effects of prostaglandin in respiratory tissue repair (31). In the present study, prostaglandin treatment in 25 -d-old rats produced only a small degree of protection, and this was linked with an activation of PKC $\epsilon$.

In conclusion, these data suggest that the increased susceptibility of the neonatal rat colon, when compared with postweaned animals, to hypoxia-mediated injury is possibly associated with a differential activation of PKC $\epsilon$ and $\delta$. The protective effect of EGF in the preweaned rat is associated with the removal of this activation, whereas the protective effect of $\mathrm{PGE}_{2}$ in the mature rat is linked in some fashion with activation of PKC $\epsilon$.

\section{REFERENCES}

1. Brown JF, Tepperman BL 1997 Ontogeny of nitric oxide synthase activity and endotoxin-mediated damage in the neonatal rat colon. Pediatr Res 41:635-640

2. Langer JC, Sigakm SS, Mumford DA 1993 Mucosal permeability in the immature rat intestine: effects of ischemia-reperfusion, cold stress, hypoxia and drugs. J Pediatr Surg 28:1380-1385

3. Brown JF, Tepperman BL 1997 Role of nitric oxide in hypoxia-induced colonic dysfunction in the neonatal rat. Am J Physiol 272:G760-G769

4. Musemeche CA, Henning SJ, Baker LL, Pizzini RP 1993 Inflammatory enzyme composition of the neonatal rat intestine: implications for susceptibility to ischaemia. J Pediatr Surg 28:788-791

5. Adams JK, Tepperman BL 2001 Colonic production and expression of IL-4, IL-6 and IL-10 in the neonatal rat after LPS challenge. Am J Physiol 280:G755-G762

6. Nishizuka Y 1992 Intracellular signaling by hydrolysis of phospholipids and activation of protein kinase C. Science 258:607-614

7. Fretland DJ, Widomski DL, Levin S, Gaginella TS 1990 Colonic inflammation in the rabbit induced by phorbol-12-myristate-13-acetate. Inflammation 14:143-150

8. Overdahl MC, Julian MW, Weisbrode SE, Dorinsky PM 1995 Anti-CD18 antibody does not block ileal injury induced by phorbol myristate acetate. Am J Respir Crit Care Med 152:1331-1336

9. Brown JF, Chang Q, Soper BD, Tepperman BL 1999 Protein kinase C mediates experimental colitis in the rat. Am J Physiol 276:G583-G590

10. Banan A, Fields JZ, Farhadi A, Talmage DA, Zhang L, Keshavarzian A 2002 Activation of $\delta$-isoform of protein kinase $\mathrm{C}$ is required for oxidant-induced disruption of both the microtubule cytoskeleton and permeability barrier of the intestinal epithelia. J Pharmacol Exp Ther 303:17-28

11. Clerk A, Bogoyevitch MA, Fuller SJ, Lazou A, Parker PJ, Sugden PH 1995 Expression of protein kinase $\mathrm{C}$ isoforms during cardiac ventricular development. Am J Physiol 269:H1087-H1097
12. Serlachius E, Svennilson J, Schalling M, Aperia A 1997 Protein kinase C in the developing kidney: isoform expression and effects of ceramide and PKC inhibitors. Kidney Int 52:901-910

13. La Porta CAM, Comoli R 1999 Age-dependent modulation of PKC isoforms and NOS activity and expression in rat cortex, striatum and hippocampus. Exp Gerontol 34:863-874

14. Thorn CE, Tepperman BL 1988 Neonatal and maternal prostaglandins in the ontogenic response of rat gastric mucosa to luminal $\mathrm{H}^{+}$. Am J Physiol 254:G142-G150

15. Tepperman BL, Soper BD 1989 Effect of epidermal growth factor on the ontogenic response of rat gastric mucosa to $\mathrm{H}^{+}$. Am J Physiol 257:G851-G859

16. Yagi KA 1976 Simple fluorometric assay for lipoperoxide in blood plasma. Biochem Res 15:212-216

17. Hsueh W, Caplan MS, Sun X, Tan X, MacKendrick W, Gonzalez-Crussi F 1994 Platelet-activating factor, tumor necrosis factor, hypoxia and necrotizing enterocolitis. Acta Paediatr Suppl 396:11-17

18. Öztürk H, Dokucu AI, Ögun C, Büyükbayram H 2002 Protective effects of recombinant human interleukin-10 on intestines of hypoxia-induced necrotizing enterocolitis in immature rats. J Pediatr Surg 37:1330-1333

19. DiLorenzo M, Krantis A 2001 Altered nitric oxide production in the premature gut may increase susceptibility to intestinal damage in necrotizing enterocolitis. J Pediatr Surg 36:700-705

20. Haykal-Coates N, Shafer TJ, Mundy WR, Barone Jr S 1998 Effects of gestational methylmercury exposure on immunoreactivity of specific isoforms of $\mathrm{PKC}$ and enzyme activity during post-natal development of the rat brain. Brain Res Dev Brain Res 109:33-49

21. Mellor H, Parker PJ 1998 The extended protein kinase C superfamily. Biochem J 332:281-292

22. Mochly-Rosen D, Khaner H, Lopez J 1991 Identification of intracellular proteins for activated protein kinase C. Proc Natl Acad Sci U S A 88:3997-4000

23. Bandla HPR, Simakajornboon N, Graff GR, Gozal D 1999 Protein kinase C modulates ventilatory patterning in the developing rat. Am J Respir Crit Care Med 159:968-973

24. Gressens P, Marret S, Bodenant C, Schwendimann L, Evrard P 1999 Activitydependent neurotrophic factor-14 requires protein kinase $\mathrm{C}$ and mitogen-associated protein kinase kinase activation to protect the developing mouse brain against excitotoxicity. J Mol Neurosci 13:199-210

25. Dvorak B, Halpern MD, Holubec H, Williams CS, McWilliam DL, Dominguez JA, Stepankova R, Payne CM, McCuskey RS 2002 Epidermal growth factor reduces the development of necrotizing enterocolitis in a neonatal rat model. Am J Physiol 282:G156-G164

26. Erickson RA, Tarnawski A, Krause WJ 1987 16,16 dimethyl prostaglandin E2 reduces chenodeoxycholate-induced small intestinal mucosal injury in the rat. J Lab Clin Med 110:387-395

27. Fretland DJ, Widomski DL, Anglin CP, Walsh RE, Levin S, Gasiecki AF, Collins PW 1992 Mucosal protective activity of prostaglandin analogs in rodent colonic inflammation. Inflammation 16:623-629

28. Banan A, Fields JZ, Talmage DA, Zhang Y, Keshavarzian A 2001 PKC- $\beta 1$ mediates EGF protection of microtubules and barrier of intestinal monolayers against oxidants. Am J Physiol 281:G833-G847

29. Banan A, Fields JZ, Farhadi A, Talmage DA, Zhang L, Keshavarzian A 2002 The $\beta 1$ isoform of protein kinase $\mathrm{C}$ mediates the protective effects of epidermal growth factor on the dynamic assembly of $\mathrm{F}$-actin cytoskeleton and normalization of calcium homeostasis in human colonic cells. J Pharmacol Exp Ther 301:852-866

30. Banan A, Smith GS, Deshpande Y, Rieckenberg CL, Kokoska ER, Miller TA 1999 Prostaglandins protect human intestinal cells against ethanol injury by stabilizing microtubules. Role of protein kinase $\mathrm{C}$ and enhanced calcium efflux. Dig Dis Sci 44:697-707

31. Kohyama T, Wyatt TA, Liu X, Wen FQ, Kobayashi T, Fang Q, Kim HJ, Rennard S 2002 PGD2 modulates fibroblast-mediated native collagen gel contraction. Am J Respir Cell Mol 27:375-381 